\title{
Instalasi Mobile-VSAT dengan Modem Radyne Comstream Berbasis SCPC (Single Carrier Personal Carrier)
}

\author{
Suci Rahmatia ${ }^{1}$, Fitria Gani Sulistya ${ }^{1}$ \\ ${ }^{1}$ Program Studi Teknik Elektro, Fakultas Sains dan Teknologi, Universitas Al Azhar Indonesia, Komplek \\ Masjid Agung Al Azhar Kebayoran Baru, Jakarta Selatan, 12110 \\ Penulis untuk Korespondensi/E-mail: suci@uai.ac.id
}

Abstrak - Teknologi komunikasi akhir-akhir ini semakin mengarah ke unsur digital. Hal ini memberikan dampak yang luar biasa bagi kehidupan manusia terutama pada bagian informasi di pemerintahan. Banyak model telekomunikasi yang digunakan, ada yang paling sederhana yaitu melalui pesawat telepon, radio, dan satelit. Komunikasi satelit menggunakan perangkat satelit yang ada di luar angkasa sebagai jembatan informasinya dengan menggunakan pemancar stasiun bumi kecil VSAT (Very Small Aperture Terminal) yang membuat dua instansi dapat berkomunikasi dengan cepat dan akurat. Tulisan ini menjelaskan tentang instalasi mobile VSAT yang biasa digunakan di Biro Teknologi Komunikasi Divisi Teknologi Informasi MABES POLRI (ROTEKKOM Div TI MABES POLRI) untuk berkomunikasi. Biasanya bagian biro menyebut VSAT bergerak ini dengan KOMOBS. Bagian - bagian yang dibahas komponen alat, cara instalasi, dan konfigurasinya.

\section{Kata kunci : Satelit, VSAT, dan Instalasi}

Abstract - Communication technology lately is increasingly leading to digital elements. This has a tremendous impact on human life, especially on the part of information in government. Many telecommunication models are used, some of the simplest is through telephone, radio, and satellite. Satellite communications use existing satellite devices in space as a bridge of information by means of a small earth station transmitter VSAT (Very Small Aperture Terminal) which allows two agencies to communicate quickly and accurately. This paper describes the installation of mobile VSAT commonly used in the Bureau of Communication Technology Division of Information Technology MABES POLRI (ROTEKKOM Div IT MABES POLRI) to communicate. Usually the bureau section calls this moving VSAT with KOMOBS. The parts discussed are tool components, installation methods, and their configuration.

Keywords: Satellite, VSAT, and Installation

\section{PENDAHULUAN}

$\mathrm{T}$ elekomunikasi sudah menjadi suatu yang penting di kehidupan. Di jaman nenek moyang yang menggunakan asap sebagai alat komunikasi dan semakin maju peradaban semakin maju pula alat komunikasinya. Di Indonesia pengembangan telekomunikasi terus dilakukan. Kebutuhan akan telekomunikasi di Indonesia saat ini sudah menjadi kebutuhan yang amat penting dan mendesak.bertumbuhnya sarana pra-sarana seperti gedung kantor, perumahan, universitas, rumah sakit, bahkan untuk menunjang sistem keamanan Negara. Salah satu yang di lakukan adalah meningkatkan fasilitas telekomunikasi pada instansi-instansi 
Negara yang bergerak dibidang keamanan seperti POLRI.

Dimulai dari system jaringan telepon dalam markas, lalu lebih meluas ke seluruh kantor cabang. Kemudian penggunaan telekomunikasi untuk mencari dan pelaporan informasi yang akurat dari tempat yang jauh menggunakan komunikasi satelit. Komunikasi satelit dinilai cukup efisien karena dapat menampilkan audio dan video sebagai informasinya. Salah satu kegunaannya adalah bisa mengakses informasi data dengan remote ip address pada modem satelit dan video conferencing.

Dalam komunikasi satelit, dikenal dengan stasiun bumi kecil atau yang lebih sering disebut dengan VSAT (Very Smal Aperture Terminal). VSAT ini banyalk digunakan sebagai alat komunikasi untuk menjangkau daerah - daerah yang tidak terjangkau oleh perangkat komunikasi lainnya.

Tetapi untuk lebih mempermudah pekerjaan, sekarang sudah ada monile VSAT. Dari namanya yaitu mobile, stasiun satelit ini dapat bergerak sesuai dengan tempat yang diinginkan untuk dilakukannya komunkasi satelit.

Hal utama yang harus diperhatikan dalam komunikasi satelit adalah modemnya. Oleh karena itu pensettingan modem satelit harus benar dan bisa dipastikan terhubung. Jika modem satelitnya sudah terhubung dengan mudah bisa di setting ke personal computer atau ke mobile satelit atau yang bisa disebut mobil KOMOBS dan flyaway.

\section{LANDASAN TEORI}

\section{Satelit}

Satelit merupakan salah satu jenis telekomunikasi yang digunakan saat ini.Secara umum, fungsi satelit adalah sebagai jembatan untuk data dimana ada bagian pengirim dan bagian penerima. Satelit buatan manusia pertama adalah Sputnik 1, diluncurkan oleh Soviet pada tanggal 4 Oktober 1957, dan memulai Program Sputnik Rusia, dengan Sergei Korolev sebagai kepala design dan Kerim Kerimov sebagai asisten nya.

\section{Cara kerja satelit}

Sebelumnya disebutkan tentang fungsi satelit yang bagaikan jembatan. Lebih jelasnya adalah sebagai berikut bahwa bentuk bumi adalah bulat dan sinyal frekuensi tinggi sifatnya LOS (Line Of Sight), sinyal hanya merambat lurus dan tidak dapat dibelokkan.Agar sinyal sampai ke tujuan maka dibutuhkan suatu repeater yang fungsinya menerima sinyal dari TX, mengubah frekuensi, menguatkan dan memancarkan kembali sehingga dapat diterima oleh RX. Yang dimaksud sebagai jembatan adalah repeater itu.

Dengan banyaknya repeater, gangguan yang muncul makin banyak dan delay timenya juga makin besar, maka untuk mengatasi kasus ini digunakan sistem satelit yang berada di angkasa luar yang berperan sebagai pengganti stasiun repeater yang ada di bumi.

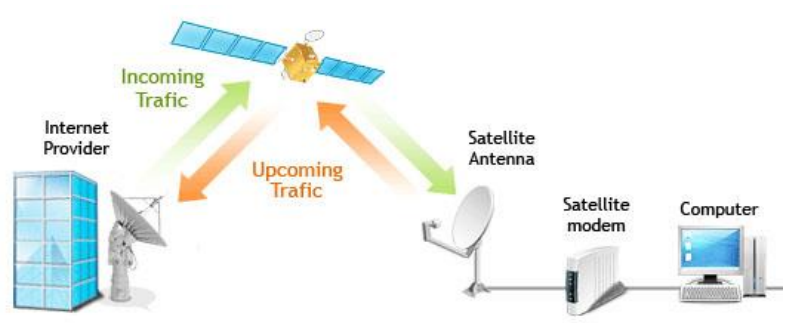

Gambar 1. Cara kerja satelit secara umum

Sistem kerja satelit adalah sistem konvensional yaitu dengan mengirimkan sinyal dari komputer dan direlai oleh satelit tanpa dilakukan pemrosesan dalam satelit.Sistem transmisi data melalui cara dengan memperhatikan komponenkomponen satelit, yaitu satelit menerima sinyal dari stasiun bumi (up-link) kemudian memperkuat sinyal, mengubah frekuensi dan mentransmisikan kembali data ke stasiun bumi penerima yang lain (down-link).

\section{VSAT (Very Small Aperture Terminal)}

Disebutkan dalam bagian cara kerja satelit bahwa satelit berfungsi sebagai repeater yang berfungsi menerima informasi yang dipancarkan (TX) lalu di teruskan oleh repeater itu dan kemudian informasi itu dipancarkan kembali ke tujuan (RX). Dalam memancarkan atau menerima sinyal informasi tersebut dibutuhkan sebuah terminal di bumi khusus untuk menerima dan memancarkan sinyal informasi tersebut. 
VSAT (Very Small Aperture Terminal) adalah stasiun penerima sinyal dari satelit dengan antena penerima berbentuk piringan dengan diameter kurang dari tiga meter.Fungsi utama dari VSAT adalah untuk menerima dan mengirim data ke satelit.Seperti yang sudah disebutkan juga bahwa satelit berfungsi sebagai penerus sinyal untuk dikirimkan ke titik lainnya di atas bumi.Sebenarnya piringan VSAT tersebut menghadap ke sebuah satelit geostasioner.

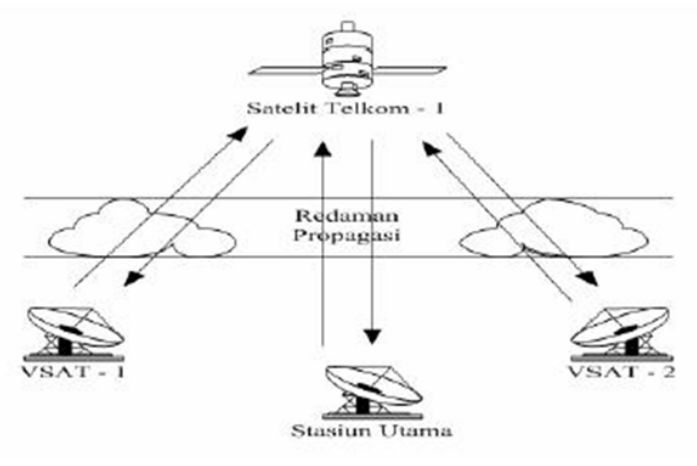

Gambar 2. Komunikasi antar dua VSAT

\section{Komponen - Komponen VSAT}

Unit Luar (Outdoor Unit (ODU)), terdiri dari:

- Satelit yang berfungsi sebagaI repeater

- Antena/dish/parabola

- $\quad$ BUC (Block Up Converter) atau RF Unit

- $\quad$ LNB (Low Noise Block Up)

Unit Dalam (Indoor Unit (IDU)), terdiri dari:

- Modem (Modulator / Demodulator)

- IFL (Inter Facility Link)

- Router

\section{PEMBAHASAN}

\section{Spesifikasi Alat}

Antena parabolic offset feed $1.8 \mathrm{~m}$

SNG Antenna menggunakan C- band (Tx : 5.925 - 6.425 Ghz, Rx : $3.7-4.2 \mathrm{GHz}$ ), IF Frequency range (Tx \& Rx : $70+/-20 \mathrm{MHz}$ ), Power output 40 Watt, dan Pointing Automatic.

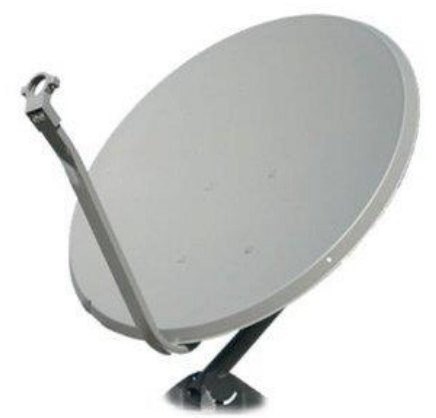

Gambar 3. Antenna dish

Untuk instalasi mobile VSAT ini, menggunakan bentuk antenna yaitu bentu offset feed.

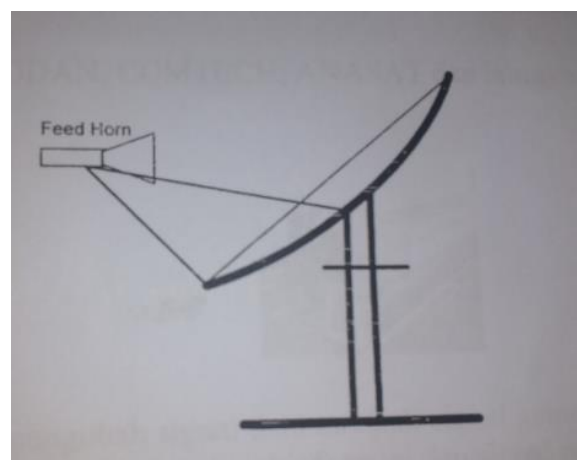

Gambar 4. Bentuk Offset Feed

\section{Satellite Modem}

- Merk : Radyne Comstream

- Modulation BPSK, QPSK, dan 8 PSK

- Data rate $2.4 \mathrm{Kbps}-5 \mathrm{Mbps}, 1 \mathrm{Bps}$ step

- FEC Viterbi 1/2,3/4, dan 7/8 . Sequential $1 / 2,3 / 4$, dan $7 / 8$.

SCPC (Single Carrier Personal Carrier) adalah system transmisi satelit VSAT yang menggunakan satu carrier untuk satu channel tersebut.

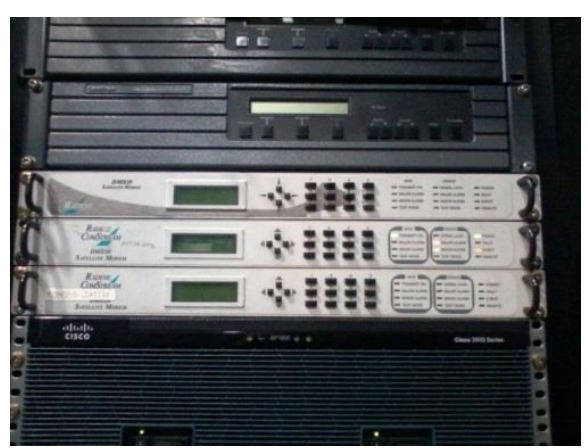

Gambar 5. Modem Radyne Comstream 


\section{RF UNIT 40 Watt Remote Console}

-Merk : CODAN 5740

-Diprogram dengan hyper terminal

-Data rate : 9600

-Data bit : 8

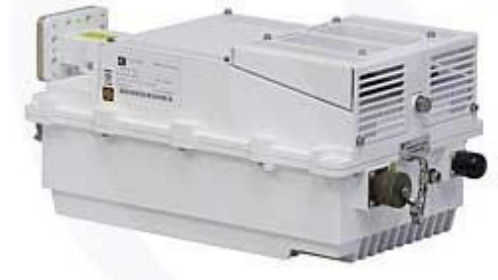

Gambar 6. salah satu contoh RF Unit, BUC CODAN 6740 40W untuk C-Band.

\section{Router CISCO series 2600 DRAM}

-Default $256 \mathrm{MB}$

-Maximum $760 \mathrm{MB}$

-Interface 4 slots

-VPN hardware acceleration

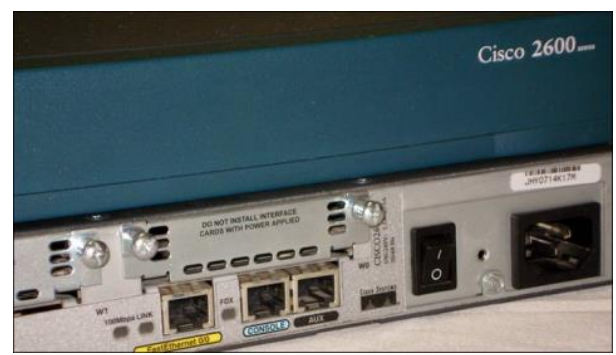

Gambar 7. Router CISCO 2600 Series

\section{Teknik Instalasi Mobile VSAT}

Seperti pada pengaplikasian suatu alat yang termasuk alat elektronika, stasiun bumi kecil atau yang sering disebut dengan VSAT memiliki standar teknik instalasi dari antenna hingga ke modem yang digunakan. Ada beberapa tahapan yang harus dipenuhi dalam menginstalasi satelit bumi ini, yaitu adalah instalasi antenna, konfigurasi modem yang digunakan, program satelit, dan konfigurasi router.

Tahap - tahap instalasi :

1. Persiapkan data survey dan parameter yang akan digunakan seperti :
- Data parameter modem dan ODU (di dapat dari pusat link satelit/ NOC)

- Data satelit dan arah antenna ke satelit (data hasil program satelit SATMASTER)

2. Dari tempat instalasi mobile VSAT yang tersedia ,usahakan agar posisi depan mobil menghadap ke arah satelit berdasarkan posisi azimuth.

3. Setelah posisi mobil sudah tepat, hidupkan engine diesel. Gerakan pedal hidrolik pengatur level antenna. Atur supaya kedudukan tiang antenna berada pada posisi tegak lurus terhadap bumi.

4. Longgarkan baut pengikat tiang antenna kemudian atur ketinggian tiang antenna secukupnya dengan menggerakan pedal hidrolik pengatur ketinggian tiang antenna.

5. Pasang spar penyanggah feedhorn pada posisi antenna yang tersedia, setelah itu pasang feedhorn dan kabel RF untuk ke ODU RF Unit.

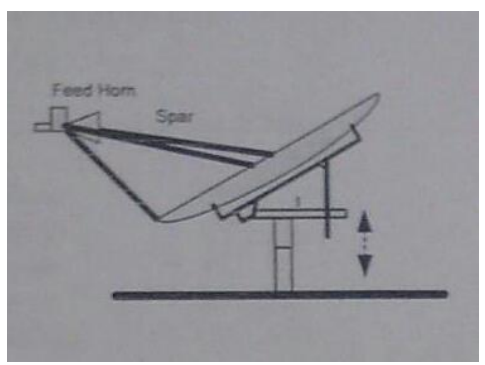

Gambar 8. Bentuk pemasangan spar pada antenna

6. Dengan koordinat yang ada atur posisi antenna sesuai arah elevasi dan azimuth ke satelit. Dengan kompas atur posisi azimuth antenna dan level angle untuk posisi elevasinya.

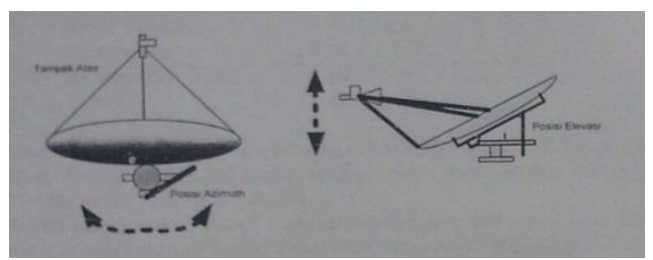

Gambar 9. Posisi azimuth dan posisi elevasi antenna.

7. Hidupkan RF Unit dan spectrum analyzer. Dengan data sinyal dari lawan dan frekuensi beacon dari satelit, dapatkan sinyal maksimal melalui spectrum analyzer. Atur 
posisi dari azimuth, elevasi, hingga posisi feedhorn untuk pengaturan maksimalnya.

8. Setup yang diperlukan untuk proses ini adalah setting frekuensi transmit modem pada posisi pure carrier (unmodulated carrier). Setting frekuensi dan attenuation RF Unit untuk posisi transponder satelit. Hasil test dapat dikirim oleh operator satelit.

9. Setelah selesai, coba test terima sinyal dari lawan/NOC dengan parameter yang telah diberikan untuk modem dan RF Unit.

Data parameter modem tersebut ialah :

- Tx IF Frequency

- Rx IF Frequency

- Tx dan Rx Data Rate : 512 Kbps

- Modulasi Tx dan Rx : QPSK

- Tx dan Rx Code Rate : VIT $3 / 4$

- Tx dan Rx Filter Type : IBS/IDR

- Tx dan Rx Scrambling: ON IDR

Kemudian data parameter ODU antara lain :

- Tx RF Frequency

- Rx RF Frequency

- Tx Attenuator : 10

- Rx Attenuator : 20

- Tx ON : YES

10. Dapatkan level EB/No dan Rx level yang cukup untuk batasan link dengan mengatur Tx power level di modem dari masing masing VSAT. Level ini bisa di lihat pada menu Monitor dan Rx Parameter di modem.

11. Setelah masing - masing VSAT telah terima level yang baik, hubungkan dan hidupkan router ke satelit modem. Setting router sesuai data yang diberikan dari NOC, test ping ke lawan melalui console router untuk memastikan link tersebut sudah berjalan. Pada pensettingan router menggunakan program Hyper Terminal.

Data router yang diberikan antara lain adalah :

- IP Address Ethernet

- IP Address Serial

- Default Gateway

Tahapan yang sudah disebutkan diatas merupakan tahapan yang dapat dikatakan mencakup semua teknik instalasi mobile VSAT. Jika semua tahapan sudah selesai, sinyal Rx dan TX didapatkan yang baik, perangkat mobile VSAT ini sudah bisa digunakan.

\section{Proses - proses instalasi}

Proses Deploy

- Pastikan hal - hal yang harus diperhatikan sudah terpenuhi (sepertiposisi antenna, dll.)

- Pada Antenna Driver di monitor, pilih menu Deploy, lalu tekan backspace untuk confirm.

- Pilih menu locate, lalu pilih TELKOM-1 SAT list. Lalu backspace lagi untuk confirm

- Pada modem pilih menu demodulator, pastikan bit rate, frekuensi dan power carrier sesuai plan NCS.

- Hidupkan ODU, perhatikan level RF pada antenna driver

- Setelah locate dan level RF terbaca, perhatikan modem pada menu MonitorEB/No.

- Atur polarisasi feedhorn dengan tekan 3 bersamaan dengan memperhatikan nilai EB/No pada modem.

- Pada saat indicator signal lock maka EB/No mulai menunjukan nilai, atur sampai mendapat EB/No tertinggi.

- Perbaiki nilai EB/No bila memungkinkan dengan mengatur azimuth dan elevasi. Pilih menu Modulator pada modem.

- Pastikan bit rate, power carrier dan frekuensi sesuai.

- $\quad$ Pilih carrier dan set on (Tx) pada modem.

\section{Proses Stow}

- Pada modem pilih menu modulator, IF, kemudian Carrier set off.

- Matikan supply ODU.

- Pada antena driver pilih menu stow, tekan backspace untuk confirm.

- Antenna akan menutup setelah proses ini selesai

- Proses stow selesai, modem akan menunjukan indicator signal unlock dengan alarm, dan antenna driver pada tampilan menu.

- Matikan semua peralatan

\section{Hal yang harus diperhatikan saat instalasi}

Setiap penginstalan sesuatu benda pasti terdapat syarat syarat yang harus diperhatikan agar tidak terjadi kesalahan atau agar hasil yang didapatkan maksimal. Dalam instalasi mobile VSAT ini 
terdapat beberapa hal yang harus diperhatikan, yaitu :

- Kendaraan menghadap keselatan bila berada di lintang selatan dan menghadap keutara bila berada di lintang utara.

- Saat adjusting flat, kendaraan harus hidup.

- Kendaraan harus dalam posisi flat/rata terhadap permukaan tanah.

- Arah disk terhadap satelit tidak terhalang/terdapat obstacle.

- $\quad$ Bila menggunakan genset, perhatikan timer oli mesin genset dan cek bahan bakar.

- Jangan mengisi solar pada saat genset hidup.

- Pastikan tegangan sudah stabil, kondisi switch high sebelum switch panel on.

- Ruang pergerakan disk harus bebas minimal 1 meter kiri-kanan kendaraan.

- Perhatikan EB/No, lebih tinggi lebih bagus.

- Power jangan sampai berlebihan, karena bisa mengakibatkan ledakan atau mengganggu satelit terdekat.

- Perhatikan mengisi IF (Intermediate Frequency) dengan benar.

\section{KESIMPULAN}

Dalam komunikasi satelit, satelit luar angkasa berperan sebagai repeater yang berfungsi menerima informasi yang dipancarkan (TX) lalu di teruskan oleh repeater itu dan kemudian informasi itu dipancarkan kembali ke tujuan $(\mathrm{RX})$. Dalam mengirimkan atau menerima informasi dari suatu tempat dengan satelit, dibutuhkan sebuah terminal yang berfungsi sebagai pemancar.

VSAT(Very Small Aperture Terminal) adalah sebuah terminal atau stasiun pemancar dari satelit di bumi yang berbentuk antenna piringan. Fungsinya adalah sebagai pemancar informasi. Lbiasanya belkerka pada frekuensi C-Band dan Ku-Band.
Semakin berjalannya teknologi, karena bentuknya yang kecil dan komponennya yang relative mudah. VSAT hanya memerlukan modem, router, RF Unit, kabel link yang biasanya berbentuk koaksial, lalu multiplexer dan antenna dish, VSAT dapat di bawa-bawa dengan menggunakan mobil agar informasi yang didapatkan akurat dan sesuai dengan operasi yang berlangsung.

Seperti yang ada di instansi MABES POLRI yang menggunakan mobile VSAT untuk keperluan operasional maupun non-operasional seperti Video Conferencing untuk rapat harian. Data parameter yang dibutuhkan dalam pengoperasian VSAT baik instalasi maupun konfigurasi modem dan router ada banyak, tetapi yang paling utama adalah IP Address Ethernet,IF, dan juga frekuensi RX \& TX.

Banyak kelebihan yang ditawarkan dengan penggunaan VSAT, seperti instalasinya yang mudah,jangakaun informasi yang luas dan cepat. Disamping memiliki keuntunga, ada beberapa kelemahan yang dimiliki komunikasi menggunakan VSAT, antara lain keamanan kurang terjamin, alat-alat yang relative mahal dan mudah terganggu cuaca. Walaupun seperti itu, komunikasi satelit masih menjadi yang paling efisien di instansi ini

\section{DAFTAR PUSTAKA}

[1] Anonim. Buku Pelatihan KOMOBS. ROTEKKOM Div TI, MABES POLRI, Jakarta, 2014. 